\title{
METODOLOGIA PARA CLASSIFICAÇÃO DO ÍNDICE DE PERIGO (IP) EM BARRAGENS DE REJEITO DA MINERAÇÃO
}

\author{
METHODOLOGY FOR CLASSIFICATION OF HAZARD INDEX (iP) IN MINING TAILINGS DAMS
}

Lucas Gomes de ALMEIDA ${ }^{1}$; Rosyelle Cristina CORTELETTI ${ }^{1}$; Luiz Fernandes DUTRA ${ }^{2}$

${ }^{1}$ Universidade Federal de Ouro Preto - Núcleo de Geotecnia da Escola de Minas (NUGEO), Campus Morro do Cruzeiro - Ouro Preto, Minas Gerais. Emails: almeidalucas.bh@gmail.com; rosyelleccorteletti@gmail.com

${ }^{2}$ Universidade de São Paulo - Instituto de Geociência Programa de Pós-Graduação em Recursos Minerais e Hidrogeologia, Rua

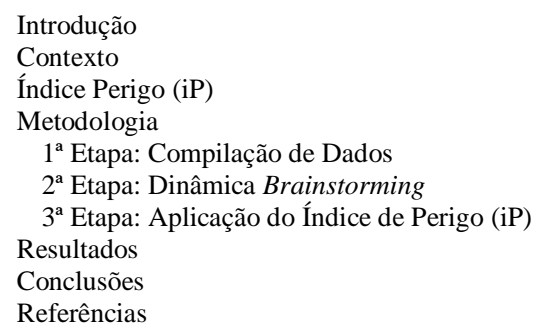

RESUMO - É de suma importância que as barragens, em especial as de rejeito da mineração, apresentem níveis satisfatórios e aceitáveis de segurança. Assim, o presente trabalho propõe a criação de uma metodologia para determinação e classificação de índices de perigo (iP) e o mapeamento de potenciais impactos associados à essas estruturas em situações hipotéticas de ruptura. A pesquisa propõe a utilização de um método de hierarquização multicriterial, conhecido como Analytic Hierarchy Process (AHP) e caracterizado pela diminuição de subjetividade durante as avaliações. Destaca-se que esse tipo de ferramenta, além do caráter objetivo, permite a avaliação das medidas de prevenção que garantem a segurança e minimizam possíveis eventos. Após a quantificação e da aplicação de técnicas estatísticas, foi realizada a classificação de cada uma das estruturas avaliadas quanto ao grau de perigo, por exemplo, em baixo, médio e alto. Finalmente, com base nos resultados obtidos, principalmente para a barragem de Fundão, conclui-se que a metodologia proposta mostrou-se eficaz e com viabilidade prática, podendo ser útil às empresas do ramo de mineração. Verifica-se também que ela permite ações mitigadoras e a redução de eventos que possam contribuir para o rompimento dessas barragens, propósito dos programas de gestão para empreendimentos desta natureza.

Palavras-chave: Barragens; Índice de perigo - iP; Analytic Hierarchy Process - AHP; Fundão.

\begin{abstract}
It is utmost importance that dams, especially those of mining tailings, presents satisfactory and acceptable levels of safety. Thereby, the present work proposes the creation of a methodology for determination and classification of hazard index es and mapping of potential impacts associated with these structures on hypothetical situations of dam break. The research proposes the use of a multicriteria hierarchy method, known as Analytic Hierarchy Process (AHP) and characterized by decrease of subjectivity during evaluations. Stands out that this type of tool, beyond objective character, allows prevention measures evaluation that ensure the safety and minimize possible events. After quantification and application of statistical techniques, was performed classification of each one evaluated structures according to their danger degree, for example, low, medium and high. Finally, based on obtained results, mainly for Fundão dam, it is concluded that proposed methodology proved to be effective and with practical feasibility, being able to be useful for mining companies. It is also verified that it allows mitigating actions and reduction of events that may contribute to these dams break, purpose of management programs for such ventures.
\end{abstract}

Keywords: Dams; Hazard index - iP; Analytic Hierarchy Process - AHP; Fundão.

\section{INTRODUÇÃO}

As barragens, utilizadas desde milhares de anos atrás, são estruturas que possuem a função de barrar água, seja para o abastecimento humano e animal (pecuária e criação de animais) ou para a indústria e para agricultura (irrigação). Além dessas aplicações, elas podem ser também utilizadas para geração de energia, controle de cheias, prática de esportes, paisagismo e para navegação. Segundo Cruz (1996) essas estruturas de contenção podem ainda ser classificadas em dois grandes grupos, conforme o material utilizado para a sua construção, são eles: as barragens de concreto e as barragens de terra e/ou enrocamento (material granular). Esse último grupo, além de ser o mais empregado no Brasil, possuem especial interesse, uma vez que serão alvos de estudo desta pesquisa.

Dessa forma, as barragens de rejeito se apresentam como estruturas construídas para conter os resíduos da mineração, as quais utilizam os próprios estéreis do empreendimento (claramente sem valor econômico) em substituição ao material granular.

Essas obras estão associadas às tecnologias de 
baixo custo e são realizadas em múltiplas etapas, conhecidas como alteamentos, conforme a quantidade de rejeito produzido (Schembri, 2016). A avaliação do perigo de ruptura de barragens de rejeito é o primeiro passo para a análise e avaliação de riscos oferecidos por esse tipo de estrutura. Neste caso, a compreensão do risco se caracteriza pela identificação do perigo potencial existente de ruptura e na possibilidade de quantificá-lo. Como consequência à evolução desses processos, surge um novo ramo de estudo, baseado no gerenciamento de risco (CNPGB, 2005).

Esse modelo de avaliação de consequências (pós-ruptura), propiciando uma compreensão das implicações e incertezas envolvidas, tem como objetivo procura dar segurança para o empreendedor e seus alvos potenciais, sejam eles o meio ambiente (fauna e flora), as edificações e, principalmente, as vidas humanas.

\section{CONTEXTO}

O tema deste trabalho está, tanto no Brasil como no restante do mundo, cada vez mais atual e debatido. O rompimento da barragem de rejeito de Fundão, por exemplo, da empresa Samarco Mineração S. A., no município de Mariana (MG), em novembro de 2015 - que destruiu todo o distrito de Bento Rodrigues e vitimou 19 pessoas - é visto como um dos maiores desastres mundiais do gênero nos últimos 100 anos. Além dessa ocorrência, cita-se ainda a ruptura das barragens da Herculano Mineração (2014), em Itabirito, com pelo menos 3 óbitos, e da Rio Pomba Cataguases (2007), em Miraí, que deixou mais de 4.000 pessoas desalojadas, ambas no estado de Minas Gerais.

$\mathrm{O}$ objetivo geral deste trabalho diz respeito à criação de uma metodologia que estabeleça parâmetros que permitam a aplicação de uma técnica de hierarquização para determinação do índice de perigo (iP) e de potenciais impactos em unidades de análises (barragens, bacias e sub-bacias hidrográficas associadas).

Em face às complexidades e aos fatos supracitados, a pesquisa justifica-se pela necessidade crescente de mapear o perigo e o risco de rompimento dessas estruturas, além de uma análise criteriosa dos danos potenciais associados às elas. Desta forma, na hipótese de ruptura, os resultados poderão ser decisivos para eficácia de políticas, principalmente interven-cionistas, voltadas à ocupação humana e ao gerenciamento dos riscos.

\section{ÍNDICE DE PERIGO (iP)}

Primeiramente, Corteletti \& Filgueiras (2015) desenvolveram a metodologia para classificação do índice de perigo (iP) aos movimentos gravitacionais de massa. Este estudo foi realizado nas encostas do Morro do Itararé, localizado no limite dos municípios de São Vicente e Santos, na região da serra do Mar, no estado de São Paulo.

Nesta pesquisa, foi desenvolvida a Equação 1 com a função de expressar as condições de um bloco (ou um conjunto deles), ao se movimentar, atingir uma determinada edificação instalada em algum ponto da encosta natural. Ressalta-se que nessa mobilidade foram consideradas as mais diversas formas possíveis de movimento, seja por queda, deslizamento, tombamento ou rolamento (movimentos de massa em rocha). Já a escolha dos parâmetros para determinação do índice de perigo (iP) foram feitas a partir das características de contorno, estudadas na literatura geotécnica como "o fenômeno da queda de bloco".

$$
i P=\sum_{i=1}^{n}\left(P_{i} x A t_{i}\right)
$$

Sendo:

$P$ - parâmetro de potencial para o movimento de bloco;

At - atributos de potencialidade para o movimento de bloco;

$n$ - número de pontos inspecionados.

Os índices de perigo (iP) nesse trabalho foram identificados ao longo da encosta, por meio de pontos, que possuíam potencial em atingir as edificações. Essa identificação ocorreu após a análise dos parâmetros, qualitativos e quantitativos, e a inserção dos respectivos atributos, cujas características poderiam desencadear um movimento de massa em rochas. Além disso, reitera-se que no caso supramencionado, os valores ponderais, de parâmetros e atributos, foram julgados em forma de pesos, conforme proposto por Saaty (1991) em sua Escala de Razão ou Escala Fundamental (Tabela 1). 
Tabela 1 - Escala de Razão. Fonte: Saaty (1991).

\begin{tabular}{|c|c|c|}
\hline $\begin{array}{l}\text { INTENSIDADE DE } \\
\text { IMPORTÂNCIA }\end{array}$ & DEFINIÇÃO & EXPLICAÇÃO \\
\hline 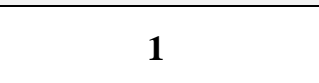 & Mesma importância & $\begin{array}{c}\text { As duas atividades contribuem igualmente para o } \\
\text { objetivo. }\end{array}$ \\
\hline 3 & $\begin{array}{c}\text { Importância pequena de uma sobre a } \\
\text { outra }\end{array}$ & $\begin{array}{c}\text { A experiência e o julgamento favorecem } \\
\text { levemente uma atividade em relação à outra. }\end{array}$ \\
\hline 5 & Importância grande ou essencial & $\begin{array}{c}\text { A experiência e o julgamento favorecem } \\
\text { fortemente uma atividade em relação à outra. }\end{array}$ \\
\hline 7 & $\begin{array}{l}\text { Importância muito grande ou } \\
\text { demonstrada }\end{array}$ & $\begin{array}{l}\text { Uma atividade é muito fortemente favorecida em } \\
\text { relação à outra; sua dominação de importância é } \\
\text { demonstrada na prática. }\end{array}$ \\
\hline 9 & Importância absoluta & $\begin{array}{c}\text { A evidência favorece uma atividade em relação à } \\
\text { outra com o mais alto grau de certeza }\end{array}$ \\
\hline $2,4,6$ e 8 & $\begin{array}{l}\text { Valores intermediários entre os valores } \\
\text { adjacentes }\end{array}$ & $\begin{array}{c}\text { Quando se procura uma condição de compromisso } \\
\text { entre duas definições. }\end{array}$ \\
\hline $\begin{array}{l}\text { Recíprocos dos } \\
\text { valores acima de } \\
\text { zero }\end{array}$ & $\begin{array}{l}\text { Se a atividade i recebe uma das } \\
\text { designações diferentes acima de zero, } \\
\text { quando comparada com a atividade j, } \\
\text { então j tem o valor recíproco quando } \\
\text { comparada com } \mathrm{i} \text {. }\end{array}$ & Uma designação razoável. \\
\hline Racionais & Razões resultantes da escala & $\begin{array}{c}\text { Se a consistência tiver de ser forçada para obter } \\
\text { valores numéricos n, somente para completar a } \\
\text { matriz. }\end{array}$ \\
\hline
\end{tabular}

Essa escala apresenta a variação de intensidade 1 a 9 , em que 1 que exprime a indiferença de importância de um parâmetro em relação ao outro e 9 revela a extrema importância de um parâmetro sobre outro. Entre as duas intensidades, estão os estágios intermediários de importância, sejam eles 2, 4, 6 e 8.

Corteletti \& Filgueiras (2016), no ano seguinte, empregaram a mesma metodologia para classificação do índice de perigo (iP) aos taludes marginais do reservatório da Usina Hidrelétrica (UHE) de Aimorés, no estado de Minas Gerais. Nesse trabalho, a determinação do índice de perigo (iP) foi feita por meio das características de contorno discutidas na literatura, tendo como princípio, a ocorrência desses eventos em "áreas marginais de reservatórios desencadeados ou acelerados devido ao processo de deplecionamento do lago".

A classificação do índice de perigo (iP) desse trabalho também apontou os pontos da margem do reservatório que tinham potencial para escorregamentos e/ou processos erosivos. Essa identificação foi de suma importância, uma vez que, como consequência a esses movimentos, uma ou mais estruturas instaladas na área poderiam ser atingidas.

Finalmente, a lógica de classificação do índice de perigo (iP) foi adotada também por Donasollo et al. (2017). Nessa situação, o estudo teve como foco os movimentos gravitacionais de massa em rodovias, tendo como estudo de caso, a rodovia RS-115, em Taquara, na região de Gramado (RS). No trabalho, a quantificação e a aplicação do índice de perigo (iP) ainda considerou os movimentos e os escorregamentos que poderiam afetar a rodovia.

\section{METODOLOGIA}

Ante aos argumentos apresentados, o presente trabalho foi desenvolvido em três etapas principais e desenvolvido para que se obtenha a classificação do índice de perigo (iP) em barragens de rejeito da mineração.

Assim, na primeira etapa foi realizada uma revisão bibliográfica e uma compilação de dados existentes na literatura geológico-geotécnica. Entre os principais levantamentos, destacam-se as legislações vigentes acerca do tema e as principais técnicas de análise de perigo e risco associados à essas infraestruturas.
Já a segunda etapa, teve como finalidade a quantificação do índice de perigo (iP) proposto. Ressalta-se que nesta fase foram feitas a escolha e a seleção dos parâmetros de avaliação, a dinâmica brainstorming para atribuição dos pesos desses parâmetros e a aplicação de uma ferramenta de hierarquização multicriterial.

Finalmente, na terceira etapa desse trabalho, foi aplicado o método do índice de perigo (iP) para quantificação e classificação dos indicadores obtidos. Nesta etapa da pesquisa, a partir dos resultados alcançados, foi possível a 
realização da classificação das barragens avaliadas e discussões acerca do assunto.

\section{$1^{\text {a }}$ Etapa: Compilação de Dados}

A partir da compilação de dados existentes, inicialmente sugere-se que sejam selecionadas uma quantidade "X" de barragens de rejeito para avaliação. Nesse trabalho, foram escolhidas seis barragens, todas elas localizadas no Quadrilátero Ferrífero (QF), porção centro-sul do estado de Minas Gerais (MG): Casa de Pedra, Doutor, Fundão, Itabiruçu, Maravilhas II e Auxiliar do Vigia. Para essa triagem, sugere-se que sejam levados em consideração fatores como: (a) a localização e posição do empreendimento em uma determinada região; (b) o(s) tipo(s) de material(is) barrado(s); (c) a(s) bacia(s) hidrográfica(s) as quais as barragens estão inseridas e; (d) a atual classificação, conforme órgãos competentes, do risco associado a essas estruturas.
Em seguida, após um criterioso processo de avaliação e separação de dados disponíveis sobre cada uma das barragens, recomenda-se que sejam levantados os parâmetros de análise.

Cerri (2006) reitera a importância desses parâmetros, uma vez que eles irão exercer papel fundamental no julgamento do índice de perigo de ruptura cada uma das estruturas. Dessa forma, como sugestão a eles foram selecionados 13 critérios, os quais são apresentados na Tabela 2.

Após a escolha dos parâmetros, foram considerados também os seus respectivos atributos que irão influenciar, direta ou indiretamente, no comportamento e na segurança da barragem de rejeitos (Saaty, 1980). No caso dessa proposta metodológica foram utilizados, para cada um dos parâmetros selecionados, 4 atributos distintos de forma que contemplem da melhor forma possível uma situação hipotética de ruptura dessas estruturas (Tabela 3 ).

Tabela 2 - Seleção e origem dos parâmetros selecionados para avaliação do perigo de ruptura de barragens.

\begin{tabular}{|c|c|c|c|}
\hline & PARÂMETRO & FONTE & OBSERVAÇÃO \\
\hline 1 & Altura da estrutura & \multirow{5}{*}{$\begin{array}{c}\text { BRASIL } \\
(2012) \\
\text { Resolução } \\
\text { Nº } 143 \text { de }_{2012 \text { do }} \\
\text { Conselho } \\
\text { Nacional } \\
\text { de } \\
\text { Recursos } \\
\text { Hídricos } \\
\text { (CNRH) }\end{array}$} & $\begin{array}{l}\text { Parâmetro para avaliação da diferença entre a elevação do ponto mais alto } \\
\text { (crista) e o ponto mais baixo (profundo) da fundação da barragem de rejeitos. }\end{array}$ \\
\hline 2 & $\begin{array}{l}\text { Tamanho do } \\
\text { coroamento }\end{array}$ & & $\begin{array}{l}\text { Parâmetro para avaliação do comprimento da superfície que delimita } \\
\text { superiormente (dique vertedor) o corpo da barragem de rejeitos (extensão } \\
\text { longitudinal da crista). }\end{array}$ \\
\hline 3 & $\begin{array}{l}\text { Impacto ambiental } \\
\text { associado }\end{array}$ & & $\begin{array}{l}\text { Parâmetro para avaliação do dano associado à área afetada a jusante de uma } \\
\text { barragem, em função da periculosidade do rejeito armazenado (classe). }\end{array}$ \\
\hline 4 & $\begin{array}{l}\text { Impacto } \\
\text { socioeconômico } \\
\text { associado }\end{array}$ & & $\begin{array}{l}\text { Parâmetro para avaliação da existência e concentração de instalações na área } \\
\text { afetada a jusante da barragem de rejeitos. }\end{array}$ \\
\hline 5 & $\begin{array}{c}\text { Existência de } \\
\text { população à jusante }\end{array}$ & & $\begin{array}{l}\text { Parâmetro para avaliação da existência (permanente ou temporária) ou não } \\
\text { de vidas humanas a jusante da barragem de rejeitos }\end{array}$ \\
\hline 6 & Volume da barragem & \multirow{4}{*}{$\begin{array}{c}\text { MIN } \\
(2002) \\
\text { Ministério } \\
\text { da } \\
\text { Integração } \\
\text { Nacional }\end{array}$} & $\begin{array}{l}\text { Parâmetro para avaliação da capacidade de armazenamento do reservatório } \\
\text { ou barragem de rejeitos. }\end{array}$ \\
\hline 7 & $\begin{array}{l}\text { Tempo de recorrência } \\
\text { ou vazão de projeto }\end{array}$ & & $\begin{array}{l}\text { Parâmetro para avaliação do período calculado para ocorrências de igual } \\
\text { magnitude de um fenômeno natural (chuvas, por exemplo) na barragem de } \\
\text { rejeitos. Geralmente, esse período (tempo de retorno ou vazão de projeto) é } \\
\text { estimado pelo inverso da probabilidade de ocorrência do fenômeno. }\end{array}$ \\
\hline 8 & Idade atual da estrutura & & $\begin{array}{l}\text { Parâmetro para avaliação do tempo (em anos) de operação da barragem de } \\
\text { rejeitos }\end{array}$ \\
\hline 9 & $\begin{array}{l}\text { Material de construção } \\
\text { utilizado }\end{array}$ & & $\begin{array}{l}\text { Parâmetro para avaliação do tipo de material empregado para construção da } \\
\text { barragem de rejeitos. }\end{array}$ \\
\hline 10 & Método construtivo & \multirow{4}{*}{ Do autor } & $\begin{array}{l}\text { Parâmetro para avaliação do tipo de construção ou de alteamento empregado } \\
\text { na barragem de rejeitos. }\end{array}$ \\
\hline 11 & $\begin{array}{l}\text { Distância da ocupação } \\
\text { urbana }\end{array}$ & & $\begin{array}{l}\text { Parâmetro para avaliação da menor distância (em linha reta) da ocupação } \\
\text { urbana mais próxima a jusante da barragem de rejeitos. }\end{array}$ \\
\hline 12 & Instrumentação & & $\begin{array}{l}\text { Parâmetro para avaliação da existência (ou não) e dos tipos de } \\
\text { instrumentação geotécnica na barragem de rejeitos. }\end{array}$ \\
\hline 13 & $\begin{array}{l}\text { Localização } \\
\text { hidrográfica (Figura 1) }\end{array}$ & & $\begin{array}{l}\text { Parâmetro para avaliação da localização da barragem de rejeitos na bacia e } \\
\text { respectiva sub-bacia hidrográfica. }\end{array}$ \\
\hline
\end{tabular}




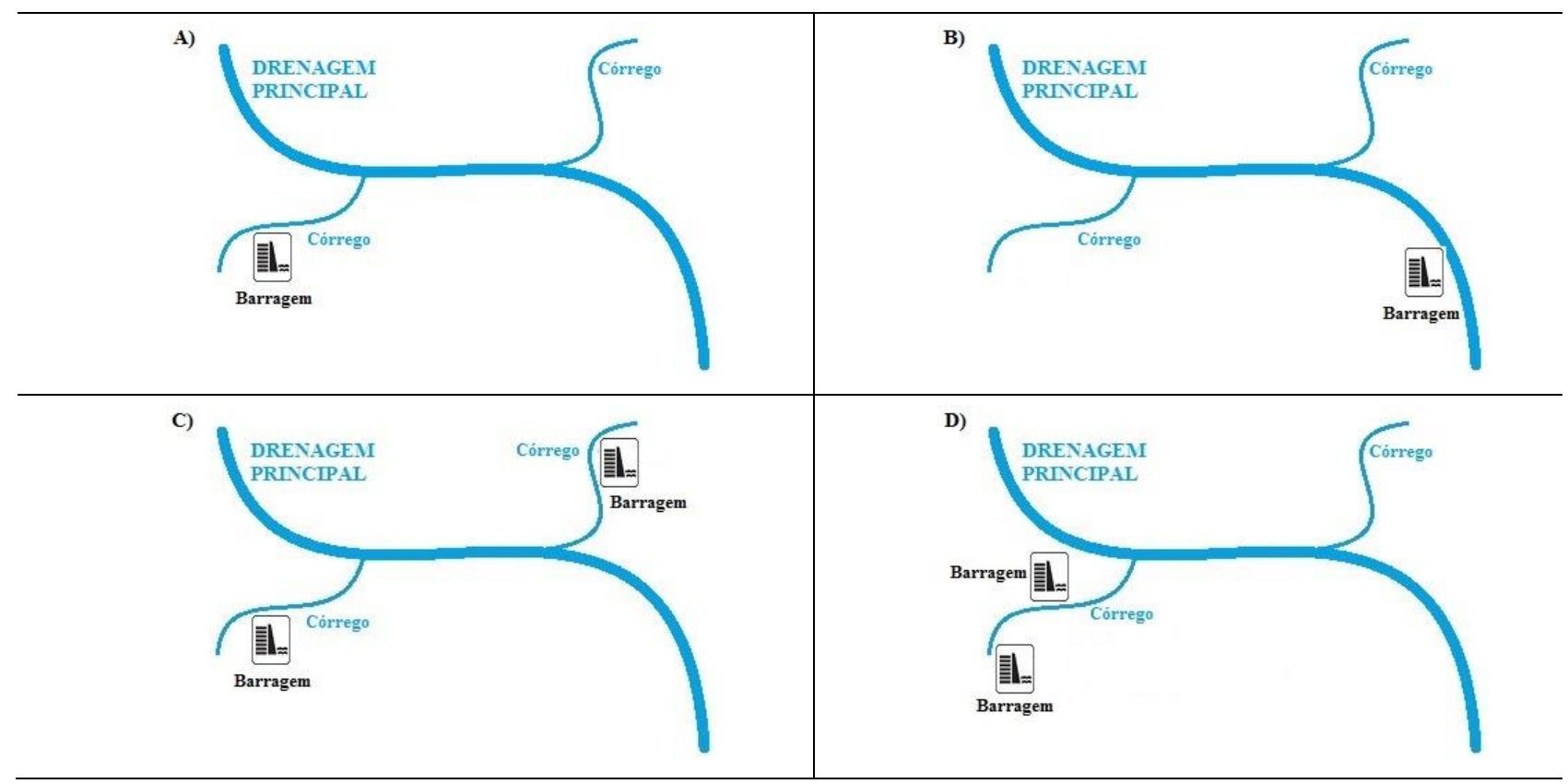

Figura 1 - Contexto para o parâmetro "Localização na bacia hidrográfica".

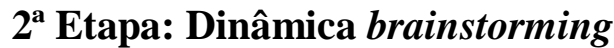

Estabelecidos os parâmetros e respectivos atributos que serão utilizados nas avaliações, teve início a $2^{\mathrm{a}}$ etapa da metodologia proposta, denominada brainstorming. Essa dinâmica tem como objetivo a valoração de notas e a redução da subjetividade durante os julgamentos e a quantificação. Essa fase é caracterizada pelo debate de especialistas da área, neste caso, de geotecnia, especificamente em barragens de rejeito da mineração.

Assim, a partir dos conceitos expostos e a necessidade de construção da hierarquia proposta, nessa etapa da pesquisa solicita-se aos especialistas o preenchimento de um formulário, o qual é apresentado por meio de uma matriz quadrada comparativa [A], que tem como base a comparação dos pares de parâmetros de análise. As comparações representam, respectivamente, a relevância de um parâmetro da "Linha $\mathrm{A}^{\text {" em }}$ relação ao parâmetro da "Coluna A", da chamada matriz de decisão (Tabela 4).

$\mathrm{O}$ processo de atribuição de notas consiste em ordená-los segundo as preferências dos especialistas, que são emitidas em forma de juízo e, então, convertidas em valores numéricos. Para valoração dos parâmetros citados na Tabela 2, neste estudo recomenda-se a Escala de Razão de Saaty (1991), apresentada na Tabela 1.

Desconsiderando-se as comparações entre os próprios parâmetros, que nesse caso estarão identificados pela diagonal principal da matriz de decisão [A] e representarão importância 1, conclui-se que apenas metade das comparações precisam ser feitas (identificadas pelas letras "a" até “j”). Neste trabalho, conforme apresentado na Tabela 4, propôs-se livremente a metade inferior à diagonal principal, uma vez que a parte superior constitui-se das comparações recíprocas. Destaca-se também que o elemento mais importante da comparação será usado sempre como um valor inteiro, e o menos relevante, por consequência, como o seu inverso, sempre menor do que 1.

Por fim, identifica-se que os julgamentos se baseiam, sumariamente, na resposta do seguinte questionamento: "Tendo-se em vista o objetivo principal, qual desses dos dois parâmetros é mais importante e qual a sua intensidade em relação ao outro?".

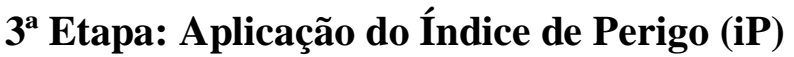

A aplicação da metodologia para classificação do índice de perigo (iP), sua proposição e adaptação para o contexto em estudo, são partes da última etapa de organização do método. Assim, para fins de aperfeiçoamento das abordagens de avaliação do perigo, considera-se pertinente a utilização de uma técnica que possa diminuir a subjetividade das análises em barragens de rejeito. Neste sentido, recomendase a utilização do método AHP (Analitic Hierarchy Process) - ou Processo de Análise Hierárquica, um dos métodos aplicáveis à hierarquização dos setores em risco (Grandzol, 2005, Braunschweig \& Becker 2004, Huang 2004, Chan et al. 2004).

Destaca-se que a grande vantagem desse método é a possibilidade de se alternar entre 
etapas de cálculo e de diálogo, ou seja, atividades que pressupõem uma intervenção contínua e direta dos responsáveis e não somente na definição do problema (Baasch, 1995). Basicamente, o método procura definir pesos aos fatores dos níveis mais baixos da hierarquia que irão interferir no objetivo geral, como por exemplo, a influência do parâmetro "altura" no processo de estabilidade de uma barragem.

Tabela 3 - Parâmetros e respectivos atributos de análise do perigo de ruptura das barragens estudadas.

\begin{tabular}{|c|c|c|}
\hline & $\begin{array}{l}\text { PARÂMETRO } \\
\text { DE ANÁLISE }\end{array}$ & ATRIBUTO \\
\hline \multirow{4}{*}{1} & \multirow{4}{*}{$\begin{array}{l}\text { Altura da } \\
\text { estrutura }\end{array}$} & Altura $\leq 15 \mathrm{~m}$ \\
\hline & & $15 \mathrm{~m}<$ altura $<30 \mathrm{~m}$ \\
\hline & & $30 \mathrm{~m} \leq$ altura $\leq 60 \mathrm{~m}$ \\
\hline & & altura $>60 \mathrm{~m}$ \\
\hline \multirow{4}{*}{2} & \multirow{4}{*}{$\begin{array}{l}\text { Extensão } \\
\text { longitudinal do } \\
\text { coroamento } \\
\text { (crista) }\end{array}$} & comprimento $\leq 50 \mathrm{~m}$ \\
\hline & & $50 \mathrm{~m}<$ comprimento $<200 \mathrm{~m}$ \\
\hline & & $200 \mathrm{~m} \leq$ comprimento $\leq 600 \mathrm{~m}$ \\
\hline & & comprimento $>600 \mathrm{~m}$ \\
\hline \multirow{4}{*}{3} & \multirow{4}{*}{$\begin{array}{l}\text { Impacto } \\
\text { ambiental } \\
\text { associado }\end{array}$} & $\begin{array}{l}\text { Pouco significativo (área afetada a jusante da barragem não apresenta área de interesse } \\
\text { ambiental relevante ou áreas protegidas em legislação específica, excluídas APP's, e armazena } \\
\text { apenas resíduos Classe II B - Inertes, segundo a NBR } 10.004 \text { da ABNT) }\end{array}$ \\
\hline & & $\begin{array}{l}\text { Significativo (área afetada a jusante da barragem apresenta área de interesse ambiental } \\
\text { relevante ou áreas protegidas em legislação específica, excluídas APP's,e armazena apenas } \\
\text { resíduos Classe II B - Inertes, segundo a NBR10.004 da ABNT) }\end{array}$ \\
\hline & & $\begin{array}{l}\text { Muito significativo (barragem armazena rejeitos ou resíduos sólidos classificados na Classe } \\
\text { II A - Não Inertes, segundo a NBR } 10004 \text { da ABNT) }\end{array}$ \\
\hline & & $\begin{array}{l}\text { Muito significativo agravado (barragem armazena rejeitos ou resíduos sólidos classificados } \\
\text { na Classe I- Perigosos segundo a NBR } 10004 \text { da ABNT) }\end{array}$ \\
\hline \multirow{4}{*}{4} & \multirow{4}{*}{$\begin{array}{l}\text { Impacto } \\
\text { socioeconômico } \\
\text { associado }\end{array}$} & Inexistente (não existem quaisquer instalações na área afetada a jusante da barragem) \\
\hline & & $\begin{array}{l}\text { Baixo (existe pequena concentração de instalações residenciais, agrícolas, industriais ou de } \\
\text { infraestrutura de relevância socioeconômico-cultural na área afetada a jusante da barragem) }\end{array}$ \\
\hline & & $\begin{array}{l}\text { Médio (existe moderada concentração de instalações residenciais, agrícolas, industriais ou de } \\
\text { infraestrutura de relevância socioeconômico-cultural na área afetada a jusante da barragem) }\end{array}$ \\
\hline & & $\begin{array}{l}\text { Alto (existe alta concentração de instalações residenciais, agrícolas, industriais ou de } \\
\text { infraestrutura de relevância socioeconômico-cultural na área afetada a jusante da barragem) }\end{array}$ \\
\hline \multirow{4}{*}{5} & \multirow{4}{*}{$\begin{array}{l}\text { Existência de } \\
\text { população à } \\
\text { jusante }\end{array}$} & $\begin{array}{l}\text { Inexistente (não existem pessoas permanentes/residentes ou temporárias/transitando na área a } \\
\text { jusante da barragem) }\end{array}$ \\
\hline & & $\begin{array}{l}\text { Pouco frequente (não existem pessoas ocupando permanentemente a área a jusante da } \\
\text { barragem, mas existe estrada vicinal de uso local) }\end{array}$ \\
\hline & & $\begin{array}{l}\text { Frequente (não existem pessoas ocupando permanentemente a área a jusante da barragem, } \\
\text { mas existe rodovia municipal ou estadual ou federal ou outro local e/ou empreendimento de } \\
\text { permanência eventual de pessoas que poderão ser atingidas }\end{array}$ \\
\hline & & $\begin{array}{l}\text { Existente (existem pessoas ocupando permanentemente a área afetada a jusante da barragem, } \\
\text { portanto, vidas humanas poderão ser atingidas) }\end{array}$ \\
\hline \multirow{4}{*}{6} & \multirow{4}{*}{$\begin{array}{l}\text { Volume da } \\
\text { barragem }\end{array}$} & Pequeno: $\leq 5.000 .000 \mathrm{~m}^{3}$ \\
\hline & & Médio: $5.000 .000 \mathrm{~m}^{3}<$ volume $\leq 25.000 .000 \mathrm{~m}^{3}$ \\
\hline & & Grande: $25.000 .000 \mathrm{~m}^{3}<$ volume $\leq 50.000 .000 \mathrm{~m}^{3}$ \\
\hline & & Muito grande: volume $>50.000 .000 \mathrm{~m}^{3}$ \\
\hline \multirow{4}{*}{7} & \multirow{4}{*}{$\begin{array}{l}\text { Tempo de } \\
\text { recorrência ou } \\
\text { vazão de } \\
\text { projeto (sistema } \\
\text { extravasor) }\end{array}$} & Decamilenar ou CMP (Cheia Máxima Provável) - TR = 10.000 anos \\
\hline & & Milenar $-\mathrm{TR}=1.000$ anos \\
\hline & & $\mathrm{TR}=500$ anos \\
\hline & & TR $<500$ anos ou Desconhecida / Estudo não confiável \\
\hline \multirow{4}{*}{8} & \multirow{4}{*}{$\begin{array}{l}\text { Idade atual } \\
\text { (tempo de } \\
\text { operação) }\end{array}$} & $>30$ anos \\
\hline & & entre 10 e 30 anos \\
\hline & & entre 5 e 10 anos \\
\hline & & $<5$ anos ou > 50 anos ou sem informação \\
\hline
\end{tabular}


Tabela 3 - Parâmetros e respectivos atributos de análise do perigo de ruptura das barragens estudadas (continuação).

\begin{tabular}{|c|c|c|}
\hline \multirow{4}{*}{9} & \multirow{4}{*}{$\begin{array}{c}\text { Tipo de } \\
\text { barragem } \\
\text { quanto ao } \\
\text { material de } \\
\text { construção }\end{array}$} & Concreto \\
\hline & & Alvenaria de pedra / Concreto rolado \\
\hline & & Terra e/ou enrocamento \\
\hline & & Terra \\
\hline \multirow{4}{*}{10} & \multirow{4}{*}{$\begin{array}{c}\text { Método } \\
\text { construtivo e/ou } \\
\text { tipos de } \\
\text { alteamentos }\end{array}$} & Linha de centro \\
\hline & & \begin{tabular}{|l} 
À jusante \\
\end{tabular} \\
\hline & & À montante \\
\hline & & 2 ou mais processos diferentes \\
\hline \multirow{4}{*}{11} & \multirow{4}{*}{$\begin{array}{l}\text { Distância }(\mathrm{d}) \\
\text { horizontal ou } \\
\text { reduzida da } \\
\text { ocupação } \\
\text { urbana }\end{array}$} & $\mathrm{d}>5 \mathrm{~km}$ \\
\hline & & $1,5 \mathrm{~km}<\mathrm{d} \leq 5 \mathrm{~km}$ \\
\hline & & $0,5 \mathrm{~km}<\mathrm{d} \leq 1,5 \mathrm{~km}$ \\
\hline & & $\mathrm{d} \leq 0,5 \mathrm{~km}$ \\
\hline \multirow{4}{*}{12} & \multirow{4}{*}{$\begin{array}{c}\text { Tipos de } \\
\text { instrumentação } \\
\text { existente }\end{array}$} & medidor de nível d'água, piezômetro, medidor de vazão, marco de superfície e batimetria \\
\hline & & medidor de nível d'água, piezômetro, medidor de vazão e marco de superfície \\
\hline & & medidor de nível d'água, piezômetro e medidor de vazão \\
\hline & & medidor de nível d'água e piezômetro \\
\hline \multirow{4}{*}{13} & \multirow{4}{*}{$\begin{array}{l}\text { Localização na } \\
\text { bacia } \\
\text { hidrográfica }\end{array}$} & A) Uma única barragem instalada sobre o córrego (ou ribeirão) \\
\hline & & B) Uma única barragem instalada sobre a drenagem principal da região \\
\hline & & $\begin{array}{l}\text { C) Duas ou mais barragens instaladas sobre córregos (ou ribeirões) diferentes, porém na } \\
\text { mesma bacia }\end{array}$ \\
\hline & & $\begin{array}{l}\text { D) Duas ou mais barragens instaladas (em cascata) sobre o mesmo córrego (ou ribeirão) e } \\
\text { mesma sub-bacia }\end{array}$ \\
\hline
\end{tabular}

Tabela 4 - Matriz de decisão ou matriz quadrada comparativa [A].

\begin{tabular}{|c|c|c|c|c|c|c|}
\hline Coluna A & Parâmetro 1 & Parâmetro 2 & Parâmetro 3 & Parâmetro 4 & Parâmetro 5 & $\begin{array}{l}\text { Questionamento: } \\
\text { Quanto um } \\
\text { parâmetro da }\end{array}$ \\
\hline Parâmetro 1 & 1 & $1 / \mathrm{a}$ & $1 / \mathrm{b}$ & $1 / \mathrm{c}$ & $1 / d$ & relevante que o \\
\hline Parâmetro 2 & $\mathrm{a}$ & 1 & $1 / \mathrm{e}$ & $1 / \mathrm{f}$ & $1 / \mathrm{g}$ & parâmetro da "Linha \\
\hline Parâmetro 3 & $\mathrm{~b}$ & $\mathrm{c}$ & 1 & $1 / \mathrm{h}$ & $1 / \mathrm{i}$ & $\begin{array}{c}\text { A" para } \\
\text { determinação do }\end{array}$ \\
\hline Parâmetro 4 & $\mathrm{~d}$ & $\mathrm{e}$ & $\mathrm{f}$ & 1 & $1 / \mathrm{j}$ & índice de criticidade \\
\hline Parâmetro 5 & $\mathrm{~g}$ & $\mathrm{~h}$ & $\mathrm{i}$ & $\mathrm{j}$ & 1 & $\begin{array}{l}\text { rejeitos? } \\
\text { reje uma barragem de }\end{array}$ \\
\hline
\end{tabular}

\section{Aplicação da matriz hierárquica}

Após o preenchimento da matriz de comparações paritárias [A] ou matriz de decisão, estabelecida na Tabela 4, foi necessário obter o vetor de pesos relativos ou autovetor $(\vec{P})$ ou, também conhecido, vetor de prioridades da matriz. Esse vetor possui papel fundamental uma vez que fornecerá a prioridade de julgamento, em termos de importância, dos $(n)$ parâmetros avaliados.

Como proposto por Saaty (2000, segundo Pereira, 2010), para o cálculo do referido autovetor, nesse trabalho aconselha-se o algoritmo aproximado de matrizes recíprocas e consistentes, o qual é baseado na media aritmética dos valores normalizados. Portanto, primeiramente deve-se dividir cada julgamento pelo somatório dos termos da coluna em que o julgamento se encontra. A matriz resultante desse processo será denominada de matriz normalizada [A'].

Em seguida, recomenda-se a soma dos valores de cada uma das linhas da matriz normalizada [A'], os quais, após serem somados, deverão ser divididos pelo número total de parâmetros $(n)$, para obtenção do peso relativo (ou autovetor $(\vec{P})$.

\section{Consistência da matriz}

Para que uma matriz, por exemplo, a matriz comparativa $[\mathrm{A}]$ proposta nesta pesquisa, tenha 
consistência e apresente resultados adequados, é necessário que a partir de uma quantidade de dados, sejam desenvolvidos uma série de cálculos baseados na metodologia proposta por Saaty (1991). Tais cálculos deverão ser realizados para que se encontre valores aceitáveis à 2 parâmetros específicos, sejam eles, a taxa de consistência (IC) e o quociente de consistência (QC).

Assim, a partir do vetor peso relativo $(\vec{P})$ obtido e do autovalor máximo $\left(\lambda_{\text {máx }}\right)$, é necessário que se verifique a taxa de consistência (IC) da matriz [A] de julgamentos. Essa taxa é dada pela multiplicação da matriz inicial [A] pelo autovetor peso $(\vec{P})$, a qual resultará em um novo vetor $(\overrightarrow{A P})$. No caso deste trabalho, especialmente, sugere-se que a média aritmética desse novo vetor seja divida, mais uma vez, pelo autovetor $(\vec{P})$, conforme Equação 2:

$$
\lambda_{\text {máx }}=\text { média do vetor } \frac{(\overrightarrow{A P})}{(\vec{P})}
$$

Em seguida, os valores do vetor $(\overrightarrow{A P})$ deverão ser somados e divididos pelo número de parâmetros $(n)$ considerados inicialmente, obtendo-se dessa forma, o autovalor máximo $\left(\lambda_{\text {máx }}\right)$ da matriz inicial $[\mathrm{A}]$. Observa-se neste momento que, quanto mais próximo for autovalor máximo $\left(\lambda_{\text {máx }}\right)$ do número $(n)$ de componentes, mais consistentes serão os resultados desejados.

Finalmente, a partir do parâmetro anterior e da Equação 3, será possível calcular o índice de consistência (IC) da matriz comparativa [A], sendo $\left({ }^{n}\right)$ o número de parâmetros ou a ordem da matriz quadrada:

$$
I C=\frac{\lambda_{\max }-n}{n-1}
$$

Sendo:

$n$ - números de parâmetros em análise; $\left(\lambda_{\text {máx }}\right)$ autovalor máximo da matriz [A].
Nesses casos, considera-se os julgamentos com índices de consistência (IC) menores que 0,1 aceitáveis e, por isso, indica-se o prosseguimento dos cálculos na metodologia em estudo. Já para os índices maiores do que 0,1 , recomenda-se a reavaliação dos parâmetros e respectivas atribuições de pesos (julgamentos), até que a consistência diminua e atinja-se um nível aceitável.

Para garantia da consistência de uma matriz, ressalta-se também que o valor de $\lambda_{\text {máx }}$ deverá ser sempre maior que o número $(n)$ de parâmetros em análise e que quanto mais próximo de $(n)$, maior será a consistência da matriz avaliada.

Como já dito, complementarmente Saaty (1991) propõe ainda mais recurso para avaliação de consistência das matrizes de julgamentos, também conhecido como quociente de consistência (QC) ou razão de consistência, que poderá ser calculado conforme Equação 4:

$$
Q C=\frac{I C}{I C A}
$$

Sendo:

$I C$ - índice de consistência;

ICA - índice de consistência Aleatória

Essa propriedade relaciona o índice de consistência (IC), obtido anteriormente, à um índice de consistência aleatória (ICA). Em relação ao último, trata-se de um número adimensional randômico, o qual foi calculado por meio de médias obtidas em testes laboratoriais (Tabela 5) e utilizado em função da ordem da matriz quadrada (ou numero " $n$ " de parâmetros selecionados).

Como regra geral, também adota-se valores para o quociente de consistência (QC) igual ou menores que 0,1 como aceitáveis. Finalmente, caso seja necessário, para valores maiores que 0,1 , recomenda-se revisões nas análises iniciais, quantas forem necessárias, em busca de menores inconsistências.

Tabela 5 - Índice randômico médio do AHP. Fonte: Saaty (1991).

\begin{tabular}{c|c|c|c|c|c|c|c|c|c|c|c|c|c|c|c}
\hline Ordem $(n)$ & $\mathbf{1}$ & $\mathbf{2}$ & $\mathbf{3}$ & $\mathbf{4}$ & $\mathbf{5}$ & $\mathbf{6}$ & $\mathbf{7}$ & $\mathbf{8}$ & $\mathbf{9}$ & $\mathbf{1 0}$ & $\mathbf{1 1}$ & $\mathbf{1 2}$ & $\mathbf{1 3}$ & $\mathbf{1 4}$ & $\mathbf{1 5}$ \\
\hline ICA & 0,00 & 0,00 & 0,58 & 0,90 & 1,12 & 1,24 & 1,32 & 1,41 & 1,45 & 1,49 & 1,51 & 1,48 & 1,56 & 1,57 & 1,59 \\
\hline
\end{tabular}

\section{Classificação do índice de perigo (iP)}

Para quantificação do índice de perigo (iP) serão utilizados os pesos $\left(P_{i}\right)$, em porcentagem, obtidos por meio do autovetor $(\vec{P})$, em função do peso ponderado de cada atributo selecionado.

Finalmente, para que os resultados possam ser melhores avaliados, neste trabalho sugere-se que os valores sejam multiplicados por um fator 
100, conforme a Equação 5, uma vez que a técnica da AHP fornecerá valores em porcentagem.

$$
i P=\sum_{i=1}^{n}\left(P_{i} x A t_{i}\right) \times 100
$$

Sendo:

$n$ - números de parâmetros em análise;

$P_{i}$ - peso do parâmetro de potencial (em porcentagem) para ocorrência de ruptura em barragens de rejeitos, obtido por meio da AHP;

$A t_{i}$ - peso da potencialidade do atributo para ocorrência de ruptura das barragens de rejeitos.

De posse dos resultados obtidos, deve-se iniciar o processo de classificação dos índices encontrados.

Essa divisão tem por finalidade a distinção de graus, conforme os valores obtidos para o índice de perigo (iP).

Ressalta-se que podem ser adotados quantos níveis de perigo forem necessários para a análise, entretanto, será adotado nessa metodologia e para esse portfólio de barragens, os graus: baixo, médio e alto.

Além disso, destaca-se também que essa escolha não diz respeito ao método AHP, mas sim uma forma de complementá-lo.

Segundo Faria (2011) e estudos avaliados, opta-se pela distinção entre os níveis supracitados por meio do método estatístico de fatiamento, que leva em consideração a média aritmética $(\bar{X})$. Assim, alcançada essa média dos valores dos $(n)$ índices de perigo, outro parâmetro à ser estabelecido é o desvio padrão amostral (s), o qual poderá ser calculado pela Equação 6:

$$
S=\sqrt{\frac{\sum_{i=1}^{n}\left(i P_{i}-\bar{X}\right)^{2}}{n-1}}
$$

Sendo:

$n$ - número de barragens de rejeitos avaliadas;

$i P_{i}$ - i-ésimo índice de perigo (iP);

$\bar{X}$ - média aritmética dos índices de perigos (iP) obtidos.

Por fim, propostas a Equação 7 e a Tabela 6, definem-se os critérios para a classificação dos índices de perigo (iP). Nessa classificação, em especial, considerou-se os perigos alto e baixo, respectivamente, como a soma e a subtração da metade do desvio padrão $(s)$ em relação à média aritmética $(\bar{X})$, enquanto que para os valores intermediários, adotou-se o grau de perigo como médio (Faria, 2011). Destaca-se que nessa classificação podem ser adotadas cores, de acordo com os graus de perigo avaliados, como por exemplo, verde, amarelo e vermelho, respectivamente, para graus baixo, médio e alto.

$$
i P=\bar{X} \pm 1 / 2 s
$$

Tabela 6. Critérios para classificação das barragens de rejeito de mineração, quanto ao grau de perigo.

\begin{tabular}{c|c}
\hline Índice de Perigo & Grau de perigo \\
\hline$i P<\bar{X}-1 / 2 \mathrm{~s}$ & Baixo \\
\hline $\bar{X}-1 / 2 \mathrm{~s} \leq i P \leq \bar{X}+1 / 2 \mathrm{~s}$ & Médio \\
\hline$i P>\bar{X}+1 / 2 \mathrm{~s}$ & Alto \\
\hline
\end{tabular}

\section{RESULTADOS}

Após a dinâmica brainstorming e a partir dos dados compilados, foi possível estabelecer a matriz [A] de comparação (Tabela 7), a qual será utilizada para hierarquização dos 13 parâmetros de avaliação pré-estabelecidos.

De forma análoga, esse mesmo método de aplicação e verificação de consistência da matriz hierárquica foi realizado às notas dos atributos de cada um dos parâmetros (Tabela 8).

Em continuidade ao método AHP, primeiramente foi necessário obter a matriz normalizada [A'], isto é, uma derivada da matriz de comparação original [A].

Para isso, portanto, dividiu-se cada termo da matriz inicial pela soma de todos os termos da coluna correspondente e, em seguida, somou- 
se todos os termos de cada uma das linhas (Tabela 9).

Os resultados da soma de cada uma dessas linhas foram divididos pelo número total de parâmetros $(n)$, neste caso, 13 , para obtenção do vetor peso ou autovetor $(\vec{P})$ (Tabela 10).

Tabela 6 - Matriz quadrada para julgamento paritário dos parâmetros de avaliação propostos neste estudo.

\begin{tabular}{|c|c|c|c|c|c|c|c|c|c|c|c|c|c|}
\hline Coluna A x Linha A & 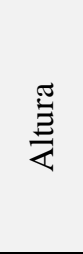 & 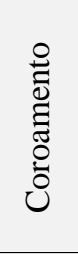 & $\begin{array}{l}\stackrel{\Xi}{\Xi} \\
\frac{\Xi}{0} \\
>\end{array}$ & 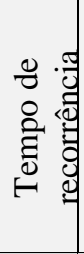 & 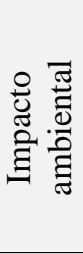 & 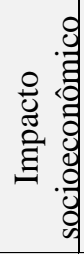 & 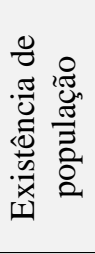 & $\frac{8}{\mathbb{Z}}$ & 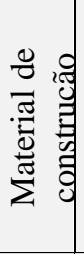 & 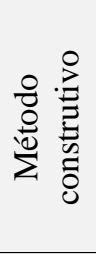 & 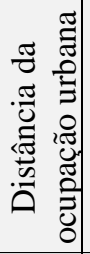 & 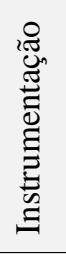 & 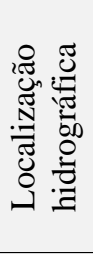 \\
\hline Altura & 1 & 1 & 1 & $1 / 3$ & $1 / 5$ & $1 / 7$ & $1 / 7$ & $1 / 3$ & $1 / 3$ & $1 / 3$ & $1 / 7$ & $1 / 5$ & $1 / 4$ \\
\hline Coroamento & 1 & 1 & 1 & $1 / 2$ & $1 / 4$ & $1 / 5$ & $1 / 7$ & $1 / 2$ & $1 / 2$ & $1 / 3$ & $1 / 6$ & $1 / 3$ & $1 / 4$ \\
\hline Volume & 1 & 1 & 1 & $1 / 2$ & $1 / 6$ & $1 / 3$ & $1 / 9$ & $1 / 2$ & $1 / 3$ & $1 / 4$ & $1 / 7$ & $1 / 3$ & $1 / 3$ \\
\hline Tempo de recorrência & 3 & 2 & 2 & 1 & $1 / 4$ & $1 / 5$ & $1 / 6$ & 1 & $1 / 2$ & $1 / 2$ & $1 / 5$ & $1 / 3$ & $1 / 2$ \\
\hline Impacto ambiental & 5 & 4 & 6 & 4 & 1 & $1 / 3$ & $1 / 3$ & 4 & 5 & 3 & $1 / 2$ & 3 & 2 \\
\hline Impacto socioeconômico & 7 & 5 & 3 & 5 & 3 & 1 & $1 / 6$ & 4 & 6 & 4 & $1 / 2$ & 4 & 4 \\
\hline Existência de população & 7 & 7 & 9 & 6 & 3 & 6 & 1 & 6 & 7 & 6 & 1 & 7 & 4 \\
\hline Idade & 3 & 2 & 2 & 1 & $1 / 4$ & $1 / 4$ & $1 / 6$ & 1 & $1 / 2$ & 2 & $1 / 4$ & $1 / 2$ & $1 / 2$ \\
\hline Material de construção & 3 & 2 & 3 & 2 & $1 / 5$ & $1 / 6$ & $1 / 7$ & 2 & 1 & $1 / 2$ & $1 / 5$ & $1 / 3$ & $1 / 3$ \\
\hline Método construtivo & 3 & 3 & 4 & 2 & $1 / 3$ & $1 / 4$ & $1 / 6$ & $1 / 2$ & 2 & 1 & $1 / 5$ & $1 / 2$ & $1 / 3$ \\
\hline $\begin{array}{r}\text { Distância da ocupação } \\
\text { urbana }\end{array}$ & 7 & 6 & 7 & 5 & 2 & 2 & 1 & 4 & 5 & 5 & 1 & 5 & 4 \\
\hline Instrumentação & 5 & 3 & 3 & 3 & $1 / 3$ & $1 / 4$ & $1 / 7$ & 2 & 3 & 2 & $1 / 5$ & 1 & 4 \\
\hline Localização hidrográfica & 4 & 4 & 3 & 2 & $1 / 2$ & $1 / 4$ & $1 / 4$ & 2 & 3 & 3 & $1 / 4$ & $1 / 4$ & 1 \\
\hline TOTAL (soma) & $\mathbf{5 0 , 0}$ & 41,0 & 45,0 & 32,3 & 11,5 & 11,4 & $\mathbf{3 , 9}$ & 27,8 & 34,2 & 27,9 & 4,8 & 22,8 & 21,5 \\
\hline
\end{tabular}

Tabela 7 - Parâmetros e atributos de análise e suas respectivas notas.

\begin{tabular}{|c|c|c|c|}
\hline & $\begin{array}{c}\text { PARÂMETRO DE } \\
\text { ANÁLISE }\end{array}$ & NOTAS & ATRIBUTO \\
\hline \multirow{4}{*}{1} & \multirow{4}{*}{ Altura da estrutura } & 0 & Altura $\leq 15 \mathrm{~m}$ \\
\hline & & 1 & $15 \mathrm{~m}<$ altura $<30 \mathrm{~m}$ \\
\hline & & 4 & $30 \mathrm{~m} \leq$ altura $\leq 60 \mathrm{~m}$ \\
\hline & & 7 & altura $>60 \mathrm{~m}$ \\
\hline \multirow{4}{*}{2} & \multirow{4}{*}{$\begin{array}{c}\text { Extensão } \\
\text { longitudinal do } \\
\text { coroamento (crista) }\end{array}$} & 0 & comprimento $\leq 50 \mathrm{~m}$ \\
\hline & & 1 & $50 \mathrm{~m}<$ comprimento $<200 \mathrm{~m}$ \\
\hline & & 4 & $200 \mathrm{~m} \leq$ comprimento $\leq 600 \mathrm{~m}$ \\
\hline & & 7 & comprimento $>600 \mathrm{~m}$ \\
\hline \multirow{4}{*}{3} & \multirow{4}{*}{$\begin{array}{l}\text { Impacto ambiental } \\
\text { associado }\end{array}$} & 2 & Pouco significativo \\
\hline & & 6 & Significativo \\
\hline & & 8 & Muito significativo \\
\hline & & 10 & Muito significativo agravado \\
\hline \multirow{4}{*}{4} & \multirow{4}{*}{$\begin{array}{c}\text { Impacto } \\
\text { socioeconômico } \\
\text { associado }\end{array}$} & 0 & Inexistente \\
\hline & & 1 & Baixo \\
\hline & & 3 & Médio \\
\hline & & 5 & Alto \\
\hline
\end{tabular}

Após a determinação do vetor peso e como já mencionado, foi realizado a verificação de consistência da matriz de comparação dos 13 parâmetros (julgamentos), por meio de 2 métodos distintos. O primeiro dos métodos, também conhecido por Índice de Consistência (IC), sugere que preliminarmente a matriz inicial [A] seja multiplicada pelo autovetor $(\vec{P})$, obtendo-se assim um novo vetor $(\overrightarrow{A P})$, que em seguida foi dividido pelo autovetor $(\vec{P})$ (Tabelas 11 e 12 ). 
Em seguida, o somatório de cada um dos termos desse novo vetor foi dividido pelo número total de julgamentos, encontrando-se assim, o autovalor máximo $\left(\lambda_{\text {máx }}\right)$ e o Índice de Consistência (IC) da matriz de comparação inicial [A] (Equações 8 e 9). Por fim, calculouse também o Quociente ou a Razão de Consistência (QC), conforme índices randômicos apresen-tados na Tabela 4 e Equação 10.

Tabela 8 - Parâmetros e atributos de análise e suas respectivas notas (continuação).

\begin{tabular}{|c|c|c|c|}
\hline \multirow{4}{*}{5} & \multirow{4}{*}{$\begin{array}{c}\text { Existência de } \\
\text { população à jusante }\end{array}$} & 1 & Inexistente \\
\hline & & 3 & Pouco frequente \\
\hline & & 5 & Frequente \\
\hline & & 10 & Existente \\
\hline \multirow{4}{*}{6} & \multirow{4}{*}{$\begin{array}{l}\text { Volume da } \\
\text { barragem }\end{array}$} & 3 & Pequeno \\
\hline & & 5 & Médio \\
\hline & & 7 & Grande \\
\hline & & 10 & Muito grande \\
\hline \multirow{4}{*}{7} & \multirow{4}{*}{$\begin{array}{c}\text { Tempo de } \\
\text { recorrência ou } \\
\text { vazão de projeto } \\
\text { (sistema extravasor) }\end{array}$} & 1 & Decamilenar \\
\hline & & 2 & Milenar - TR = 1.000 anos \\
\hline & & 4 & $\mathrm{TR}=500$ anos \\
\hline & & 10 & $\mathrm{TR}<500$ anos ou Desconhecida \\
\hline \multirow{4}{*}{8} & \multirow{4}{*}{$\begin{array}{l}\text { Idade atual (tempo } \\
\text { de operação) }\end{array}$} & 0 & $>30$ anos \\
\hline & & 1 & entre 10 e 30 anos \\
\hline & & 2 & entre 5 e 10 anos \\
\hline & & 3 & $<5$ anos ou > 50 anos ou sem informação \\
\hline \multirow{4}{*}{9} & \multirow{4}{*}{$\begin{array}{l}\text { Tipo de barragem } \\
\text { quanto ao material } \\
\text { de construção }\end{array}$} & 4 & Concreto \\
\hline & & 6 & Alvenaria de pedra / Concreto rolado \\
\hline & & 8 & Terra enrocamento \\
\hline & & 10 & Terra \\
\hline \multirow{4}{*}{10} & \multirow{4}{*}{$\begin{array}{l}\text { Método construtivo } \\
\text { e/ou tipos de } \\
\text { alteamentos }\end{array}$} & 1 & Linha de centro \\
\hline & & 2 & À jusante \\
\hline & & 3 & À montante \\
\hline & & 4 & 2 ou mais processos diferentes \\
\hline \multirow{4}{*}{11} & \multirow{4}{*}{$\begin{array}{l}\text { Distância }(\mathrm{d}) \\
\text { horizontal ou } \\
\text { reduzida da } \\
\text { ocupação urbana }\end{array}$} & 3 & $\mathrm{~d}>5 \mathrm{~km}$ \\
\hline & & 5 & $1,5 \mathrm{~km}<\mathrm{d} \leq 5 \mathrm{~km}$ \\
\hline & & 8 & $0,5 \mathrm{~km}<\mathrm{d} \leq 1,5 \mathrm{~km}$ \\
\hline & & 10 & $\mathrm{~d} \leq 0,5 \mathrm{~km}$ \\
\hline \multirow{4}{*}{12} & \multirow{4}{*}{$\begin{array}{c}\text { Tipos de } \\
\text { instrumentação } \\
\text { existente }\end{array}$} & 1 & $\begin{array}{l}\text { medidor de nível d'água, piezômetro, medidor de } \\
\text { vazão, marco de superfície e batimetria }\end{array}$ \\
\hline & & 2 & $\begin{array}{l}\text { medidor de nível d'água, piezômetro, medidor de } \\
\text { vazão e marco de superfície }\end{array}$ \\
\hline & & 3 & $\begin{array}{l}\text { medidor de nível d'água, piezômetro e medidor de } \\
\text { vazão }\end{array}$ \\
\hline & & 4 & medidor de nível d'água e piezômetro \\
\hline \multirow{4}{*}{13} & \multirow{4}{*}{$\begin{array}{l}\text { Localização na } \\
\text { bacia hidrográfica }\end{array}$} & 2 & $\begin{array}{l}\text { Uma única barragem instalada sobre o córrego (ou } \\
\text { ribeirão) }\end{array}$ \\
\hline & & 5 & $\begin{array}{l}\text { Uma única barragem instalada sobre a drenagem } \\
\text { principal da região }\end{array}$ \\
\hline & & 7 & $\begin{array}{l}\text { Duas ou mais barragens instaladas sobre córregos (ou } \\
\text { ribeirões) diferentes, porém na mesma bacia }\end{array}$ \\
\hline & & 10 & $\begin{array}{l}\text { Duas ou mais barragens instaladas (em cascata) sobre } \\
\text { o mesmo córrego (ou ribeirão) e mesma sub-bacia }\end{array}$ \\
\hline
\end{tabular}

$$
\begin{gathered}
\lambda_{\text {máx }}=\frac{184,46}{13}=14,19 \\
I C=\frac{\lambda_{\text {máx }}-\mathrm{n}}{\mathrm{n}-1}=\frac{14,19-13}{13-1}=0,099
\end{gathered}
$$

$$
Q C=\frac{I C}{I C A}=\frac{0,099}{1,56}=0,064
$$

Logo, a partir da proposta de Saaty (1991) e dos valores obtidos para IC e QC (menores que 
$0,1)$, afirma-se que a matriz de parâmetros pode ser ordenada de forma hierárquica e, principalmente, por consequência, que o vetor peso obtido é considerado aceitável.

Ressalta-se que está hierarquização permitiu estabelecer, dentre todos os critérios escolhidos, qual terá maior influência na determinação do índice de perigo (iP). Nesse sentido, a Tabela 13 apresenta os pesos distributivos, de cada um dos parâmetros, em ordem decrescente de relevância.

Destaca-se ainda, neste caso, o parâmetro "Existência de população" que possui maior vetor de prioridade e logo, por consequência, apresentará maior impacto na avaliação. Por outro lado, vê-se que o parâmetro "Altura", já não influenciará tanto na determinação do índice de perigo (Figura 2).

Tabela 8 - Matriz normalizada [A'].

\begin{tabular}{|c|c|c|c|c|c|c|c|c|c|c|c|c|c|c|c|}
\hline \multirow{13}{*}[\mathbf{A}^{\prime}]{$=$} & 0,02 & 0,02 & 0,02 & 0,01 & 0,02 & 0,01 & 0,04 & 0,01 & 0,01 & 0,01 & 0,03 & 0,01 & 0,01 & & 0,23 \\
\hline & 0,02 & 0,02 & 0,02 & 0,02 & 0,02 & 0,02 & 0,04 & 0,02 & 0,01 & 0,01 & 0,04 & 0,01 & 0,01 & & 0,26 \\
\hline & 0,02 & 0,02 & 0,02 & 0,02 & 0,01 & 0,03 & 0,03 & 0,02 & 0,01 & 0,01 & 0,03 & 0,01 & 0,02 & & 0,25 \\
\hline & 0,06 & 0,05 & 0,04 & 0,03 & 0,02 & 0,02 & 0,04 & 0,04 & 0,01 & 0,02 & 0,04 & 0,01 & 0,02 & & 0,41 \\
\hline & 0,10 & 0,10 & 0,13 & 0,12 & 0,09 & 0,03 & 0,08 & 0,14 & 0,15 & 0,11 & 0,11 & 0,13 & 0,09 & & 1,38 \\
\hline & 0,14 & 0,12 & 0,07 & 0,15 & 0,26 & 0,09 & 0,04 & 0,14 & 0,18 & 0,14 & 0,11 & 0,18 & 0,19 & & $\mathbf{1 , 8 0}$ \\
\hline & 0,14 & 0,17 & 0,20 & 0,19 & 0,26 & 0,53 & 0,25 & 0,22 & 0,20 & 0,21 & 0,21 & 0,31 & 0,19 & & 3,08 \\
\hline & 0,06 & 0,05 & 0,04 & 0,03 & 0,02 & 0,02 & 0,04 & 0,04 & 0,01 & 0,07 & 0,05 & 0,02 & 0,02 & & 0,49 \\
\hline & 0,06 & 0,05 & 0,07 & 0,06 & 0,02 & 0,01 & 0,04 & 0,07 & 0,03 & 0,02 & 0,04 & 0,01 & 0,02 & & $\mathbf{0 , 5 0}$ \\
\hline & 0,06 & 0,07 & 0,09 & 0,06 & 0,03 & 0,02 & 0,04 & 0,02 & 0,06 & 0,04 & 0,04 & 0,02 & 0,02 & & $\mathbf{0 , 5 7}$ \\
\hline & 0,14 & 0,15 & 0,16 & 0,15 & 0,17 & 0,18 & 0,25 & 0,14 & 0,15 & 0,18 & 0,21 & 0,22 & 0,19 & & 2,29 \\
\hline & 0,10 & 0,07 & 0,07 & 0,09 & 0,03 & 0,02 & 0,04 & 0,07 & 0,09 & 0,07 & 0,04 & 0,04 & 0,19 & & 0,92 \\
\hline & 0,08 & 0,10 & 0,07 & 0,06 & 0,04 & 0,02 & 0,06 & 0,07 & 0,09 & 0,11 & 0,05 & 0,01 & 0,05 & & 0,81 \\
\hline
\end{tabular}

Tabela 9 - Matriz ou vetor peso.

\begin{tabular}{c|c}
\hline & 0,017 \\
\cline { 2 - 2 } & 0,020 \\
\cline { 2 - 2 } & 0,019 \\
\hline \multirow{5}{*}{$\overrightarrow{0 u} 0,032$} \\
\cline { 2 - 2 } & 0,106 \\
\cline { 2 - 2 } & 0,139 \\
\hline & 0,237 \\
\hline & 0,038 \\
\hline & 0,038 \\
\hline & 0,044 \\
\hline & 0,176 \\
\cline { 2 - 2 } & 0,071 \\
\cline { 2 - 2 } & 0,062 \\
\hline
\end{tabular}

Tabela 10 - Multiplicação da matriz [A] pelo vetor peso.

\begin{tabular}{c|c}
\hline \multirow{4}{*}{} & 0,24 \\
\cline { 2 - 2 } & 0,28 \\
\cline { 2 - 2 } & 0,28 \\
\hline & 0,43 \\
\cline { 2 - 2 } & 1,54 \\
\hline & 2,12 \\
\cline { 2 - 2 } & 3,70 \\
\cline { 2 - 2 } & 0,52 \\
\hline & 0,51 \\
\hline & 0,59 \\
\cline { 2 - 2 } & 2,61 \\
\hline & 1,04 \\
\cline { 2 - 3 } & 0,87 \\
\hline
\end{tabular}


Tabela 11 - Divisão do vetor AP pelo vetor peso.

\begin{tabular}{c|c}
\hline \multirow{4}{*}{ Vetor $(\mathbf{A P}) /$ autovetor $(\vec{P})=$} & 13,58 \\
\cline { 2 - 2 } & 13,92 \\
\hline & 14,27 \\
\hline & 13,37 \\
\cline { 2 - 2 } & 14,50 \\
\hline & 15,25 \\
\hline & 13,62 \\
\hline & 13,77 \\
\hline & 13,58 \\
\hline & 14,83 \\
\hline & 14,64 \\
\hline TOTAL $=$ & 13,85 \\
\hline & $\mathbf{1 8 4 , 4 6}$ \\
\hline
\end{tabular}

Tabela 12 - Peso distributivo dos parâmetros de avaliação do índice de perigo (iP) de uma barragem.

\begin{tabular}{l|c}
\multicolumn{1}{c|}{ Parâmetro } & Peso \\
\hline Existência de população & $23,68 \%$ \\
\hline Distância da ocupação urbana & $17,58 \%$ \\
\hline Impacto socioeconômico & $13,88 \%$ \\
\hline Impacto ambiental & $10,64 \%$ \\
\hline Instrumentação & $7,10 \%$ \\
\hline Localização hidrográfica & $6,25 \%$ \\
\hline Método construtivo & $4,38 \%$ \\
\hline Material de construção & $3,82 \%$ \\
\hline Idade & $3,77 \%$ \\
\hline Tempo de recorrência & $3,19 \%$ \\
\hline Coroamento & $2,03 \%$ \\
\hline Volume & $1,93 \%$ \\
\hline Altura & $1,75 \%$ \\
\hline
\end{tabular}

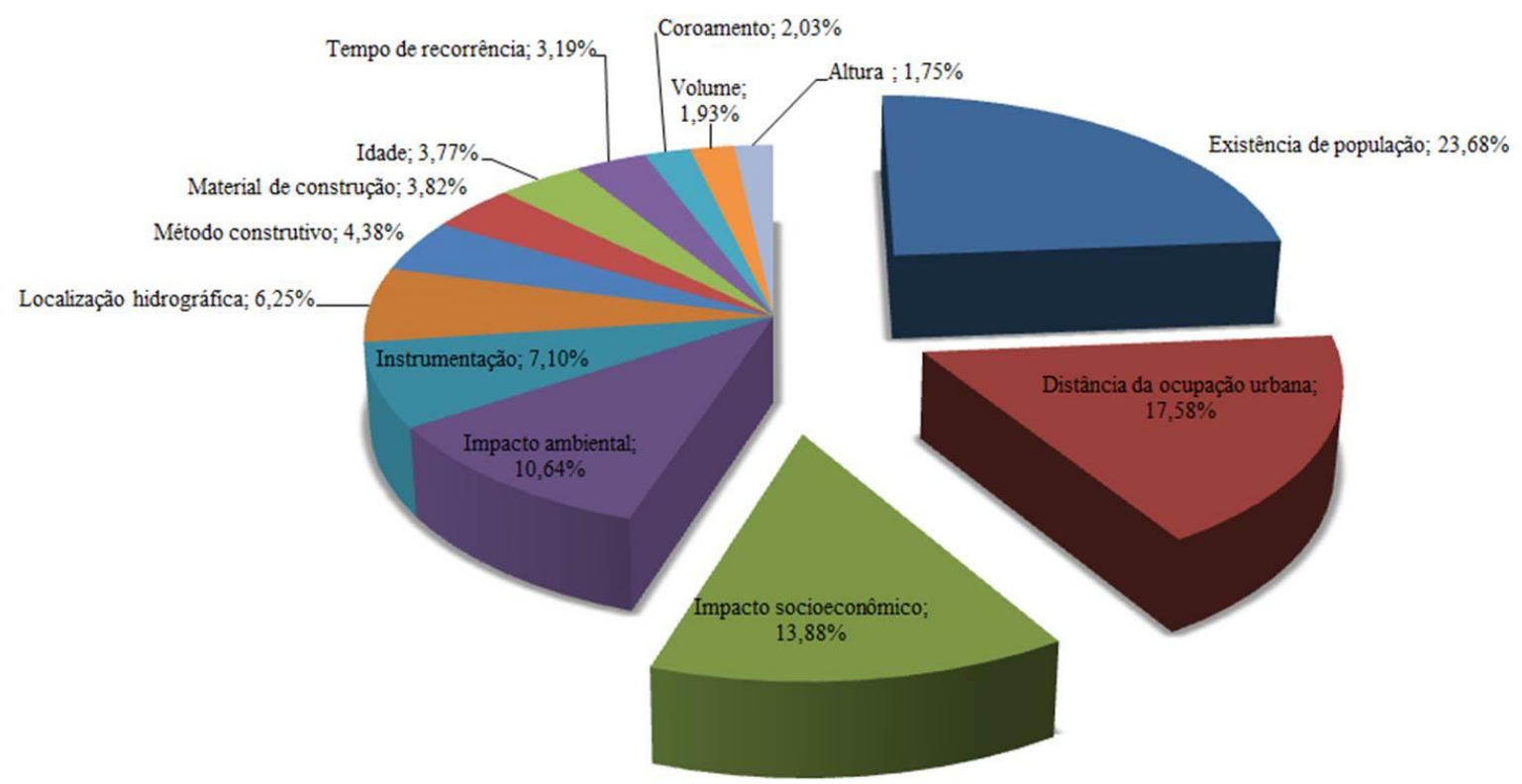

Figura 2 - Pesos distributivos com destaque para os 3 parâmetros de maior relevância.

Assim, estabelecidos todos os parâmetros $\left(P_{i}\right)$ Fundão, teve início a etapa de cálculos para e notas/pesos dos atributos ( $\left.A t_{i}\right)$, conforme quantificação dos índices de perigo (iP). Os Equação 11 e demonstração para a barragem de resultados dessa quantificação (iP) são 
apresentados na Tabela 14, em ordem decrescente, isto é, das contenções mais perigosas às menos perigosas.

$i P=\sum_{i=1}^{n}\left(P_{i} \times A t_{i}\right) \times 100$

Sendo:

$n$ - número de parâmetros em análise;

$P_{i}$ - peso do parâmetro de potencial em porcentagem para ocorrência de ruptura em barragens de rejeitos obtido por meio da AHP;

$A t_{i}$ - nota da potencialidade do atributo para ocorrência de ruptura das barragens de rejeitos.

É válido destacar os valores máximo e mínimo, respectivamente, $\mathrm{iP}=618,5$ de Fundão e iP $=446,5$ da barragem do Doutor, sendo o maior deles justificados pela relevância da existência de população à jusante.

Como exemplo didático, foi demonstrado o cálculo do índice de perigo (iP) para a barragem de Fundão, em Mariana (MG), antes de sua ruptura.

$$
\begin{aligned}
i P_{\text {Fundão }}=[ & (1,75 \% * 7)+(2,03 \% * 7) \\
& +(1,93 \% * 10)+(3,19 \% * 1) \\
& +(10,64 \% * 10) \\
& +(13,88 \% * 3) \\
& +(23,68 \% * 10) \\
& +(3,82 \% * 2)+(3,77 \% * 8) \\
& +(4,38 \% * 4)+(17,58 \% \\
& * 3)+(7,10 \% * 2)+(6,25 \% \\
& * 10)] x 100 \\
& i P_{\text {Fundão }}=618,5
\end{aligned}
$$

\begin{tabular}{|c|c|c|c|c|c|c|c|}
\hline PARÂMETROS & $\boldsymbol{P}_{i}$ & $\begin{array}{c}\text { Fundão } \\
\left(P p_{i}\right)\end{array}$ & $\begin{array}{c}\text { Auxiliar do } \\
\text { Vigia e } \\
\text { Vigia }\left(P p_{i}\right)\end{array}$ & $\begin{array}{c}\text { Casa de } \\
\text { Pedra } \\
\left(P p_{i}\right)\end{array}$ & $\begin{array}{c}\text { Itabiruçu } \\
\left(P p_{i}\right)\end{array}$ & $\begin{array}{c}\text { Maravilhas } \\
\text { II }\left(\boldsymbol{P} p_{i}\right)\end{array}$ & $\begin{array}{c}\text { Doutor } \\
\left(\boldsymbol{P} p_{i}\right)\end{array}$ \\
\hline Altura & $1,75 \%$ & 7 & 4 & 7 & 7 & 7 & 7 \\
\hline Coroamento & $2,03 \%$ & 7 & 4 & 7 & 7 & 7 & 7 \\
\hline Volume & $1,93 \%$ & 10 & 5 & 5 & 10 & 10 & 7 \\
\hline Tempo de recorrência & $3,19 \%$ & 1 & 4 & 1 & 1 & 4 & 1 \\
\hline Impacto ambiental & $10,64 \%$ & 10 & 10 & 10 & 10 & 10 & 10 \\
\hline Impacto socioeconômico & $13,88 \%$ & 3 & 5 & 5 & 5 & 1 & 1 \\
\hline Existência de população & $23,68 \%$ & 10 & 3 & 5 & 3 & 3 & 3 \\
\hline Idade & $3,82 \%$ & 2 & 1 & 1 & 0 & 1 & 1 \\
\hline Material de construção & $3,77 \%$ & 8 & 8 & 10 & 10 & 10 & 10 \\
\hline Método construtivo & $4,38 \%$ & 4 & 3 & 4 & 2 & 2 & 4 \\
\hline Distância ocupação urbana & $17,58 \%$ & 3 & 10 & 8 & 8 & 8 & 5 \\
\hline Instrumentação & $7,10 \%$ & 2 & 4 & 1 & 2 & 2 & 3 \\
\hline Localização hidrográfica & $6,25 \%$ & 10 & 10 & 2 & 7 & 7 & 7 \\
\hline TOTAL & - & 77 & 71 & 66 & 72 & 72 & 66 \\
\hline (iP) & x 100 & $\underline{618,5}$ & $\underline{598,2}$ & $\underline{552,8}$ & $\underline{540,9}$ & $\underline{498,7}$ & $\underline{446,5}$ \\
\hline
\end{tabular}

Tabela 13 - Ordem decrescente dos índices de perigo (iP), conforme vetor peso e nota de potencialidade.

O índice de perigo tem o intuito de destacar os pontos em uma área, região ou extensão, com maior possibilidade de problemas de origem geológico-geotécnica, além dos aspectos sociais e ambientais.

O índice facilita a indicação de alerta dos pontos à serem tratados e/ou que necessitam passar por algum tipo de manutenção e prevenção.

Dessa forma, torna-se de suma importância também a classificação desses resultados obtidos. Como exposto anteriormente, para tanto foi adotado o método de fatiamento estatístico, por meio da média aritmética $(\bar{X})$ e do desvio padrão (s), respectivamente, Equações 12 e 13.

$$
\begin{aligned}
& \bar{X}=542,6 \\
& s=63,5
\end{aligned}
$$

Dessa forma, o iP para situações hipotéticas de ruptura das barragens de rejeitos foram classificados nas seguintes faixas: baixo, médio e alto grau de perigo, segundo o portfólio de estruturas selecionadas (Tabelas 15 e 16). 
Tabela 14 - Classificação do grau de perigo, conforme valores do iP obtidos.

\begin{tabular}{c|c}
\hline Índice de perigo & Grau de perigo \\
\hline$i P<510,8$ & Baixo \\
\hline $510,8 \leq i \mathrm{P} \leq 574,3$ & Médio \\
\hline$i P>574,3$ & Alto \\
\hline
\end{tabular}

Tabela 15 - Classificação das barragens de rejeito alvo de estudo desse trabalho.

\begin{tabular}{c|c}
\hline Barragem & Grau de Perigo \\
\hline Fundão & Alto \\
\hline Vigia e Auxiliar do Vigia & Alto \\
\hline Casa de Pedra & Médio \\
\hline Itabiruçu & Médio \\
\hline Maravilhas II & Baixo \\
\hline Doutor & Baixo \\
\hline
\end{tabular}

\section{CONCLUSÕES}

Neste sentido, tendo em vista o acidente ocorrido na barragem de Fundão, em Mariana (MG), no ano de 2015, e a metodologia proposta com essa pesquisa, destaca-se a importância de estudos para avaliação do perigo, além de medidas efetivas de monitoramento e mitigação, de forma que tais infraestruturas apresentem níveis satisfatórios para a segurança de todos.

A partir dos resultados obtidos com o método AHP, esse trabalho permitirá que sejam constatados, entre outros fatos:

a) a diminuição de subjetividade das avaliações proposta nesse estudo, por meio da comparação entre os julgamentos e a classificação final obtida, com o somatório simples das notas de cada um dos atributos avaliados;

b) o confronto dos resultados alcançados com essa metodologia e as barragens de rejeitos analisada em outras classificações, por exemplo, a classificação de risco do Departamento
Nacional de Produção Mineral (DNPM), por intermédio do Cadastro Nacional de Barragens de Mineração (Brasil, 2010);

c) a eficiência e a confiabilidade do método, por artifício de verificação das matrizes de julgamentos (índice e razão de consistência), que estabelece pesos aos parâmetros a partir da relevância e sensibilidade de cada um deles, e não de forma heurística ou intuitiva;

d) a comprovação de que o método nada mais é do que um processo estruturado, o qual poderá ser repetido quantas vezes forem necessárias, tendo em vista o seu objetivo central;

e) o questionamento da garantia de estabilidade proposta à esses tipos de estruturas, seja mediante auditorias ou por órgãos fiscalizadores competentes;

f) a viabilidade de aplicação dessa metodologia em grupos de decisão, o que pode ser de grande valia para empresas, em especial, as do ramo da mineração.

\section{REFERÊNCIAS}

ASSOCIAÇÃO BRASILEIRA DE NORMAS TÉCNICAS (ABNT) - NBR 10.004. Classificação de Resíduos.

BAASCH, S.S.N. Um sistema de suporte multicritério aplicado na gestão dos resíduos sólidos nos municípios catarinenses. Tese de Doutorado, Engenharia de Produção e Sistemas, Universidade Federal de Santa Catarina, Florianópolis, SC, 1995.

BRASIL. Lei no 12.334, de 20 de setembro de 2010. Estabelece a Política Nacional de Segurança de Barragens destinadas à acumulação de água para quaisquer usos, à disposição final ou temporária de rejeitos e à acumulação de resíduos industriais. Brasília, 2010.

BRASIL. Resolução n ${ }^{\circ}$ 143, de 10 de junho de 2012. Estabelece critérios gerais de classificação de barragens por categoria de risco, dano potencial associado e pelo seu volume. Conselho Nacional de Recursos Hídricos (CNRH). Brasília, 2012.

BRAUNSCHWEIG, T. \& BECKER, B. Choosing research priorities by using the analytic hierarchy process: an application to international agriculture. R \& D Management [S.I.], v. 34, n. 1, 77-86, 2004.

CERRI, L.E.S. Mapeamento de Riscos nos Municípios. In: BRASIL. CARVALHO, C.S.; GALVÃO, T. (orgs.). Prevenção de Riscos de Deslizamentos em Encostas: Guia para Elaboração de Políticas Municipais. Brasília:
Ministério das Cidades; Cities Alliance, p. 46-55, 2006.

CHAN, A.H.S.; KWOK, W.Y.; DUFFY, V.G. Using AHP for determining priority in a safety management system. Industrial Management \& Data Systems, v. 104, n. 5, 430-445, 2004.

CNPGB. COMISSÃO NACIONAL PORTUGUESA DE GRANDES BARRAGENS. Grupo de Trabalho de Análise de Riscos em Barragens: $1^{\circ}$ Relatório de Progresso. Lisboa, 2005.

CORTELETTI, R.C. \& FILGUEIRAS, R.A.C. Projeto de contenção da encosta do morro do itararé - Associação dos Funcionários da Baixada Santista. São Vicente, SP. Vale Fertilizantes, 180p, 2015.

CORTELETTI, R.C. \& FILGUEIRAS, R.A.C. Identificação e análise de áreas de instabilidade geotécnica, ao longo do reservatório da UHE (Usina Hidrelétrica Eliezer Batista) Aimorés, MG. 2016.

CRUZ, P.T. 100 Barragens Brasileiras: casos históricos, materiais de construção projeto. 2 . ed. São Paulo: Oficina de Textos, 648 p., 1996.

DONASOLlO, A.; CORTELETTI, R.C.; GOMES, R.C. Identificação de pontos de perigo de movimentos de massa utilizando o método Analytic Hierarchy Process (AHP). Estudo de caso: rodovia RS-115, Taquara - Gramado, RGS. In: CONFERÊNCIA BRASILEIRA SOBRE ESTABILIDADE 
DE ENCOSTAS, Florianópolis, 2017. Anais...Florianópolis.

FARIA, D.G.M. Mapeamento de perigo de escorregamentos em áreas urbanas precárias brasileiras com a incorporação do Processo de Análise Hierárquica (AHP). São Carlos, 194p, 2011. Tese (Doutorado em Geotecnia) - Escola de Engenharia de São Carlos, Universidade de São Paulo,

GRANDZOL, J.R. Improving the Faculty Selection Process in Higher Education: a case for the analytic hierarchy process. IR Applications, v. 6, 13p, 2005.

HUANG, B. A GIS-AHP Method for HAZMAT Route Planning with consideration of Security. Environmental Informatics Archive, v. 2, 814-830, 2004.

MIN. MINISTÉRIO DA INTEGRAÇÃO NACIONAL. Manual de Segurança e Inspeção de Barragens - Brasília: Secretaria de Infraestrutura Hídrica (SIH), 148 p., 2002.

PEREIRA, R.A. Aplicação do método AHP na redução de multas em empresas de telecomunicações. Campinas, $100 \mathrm{p}$, 2010. Dissertação (mestrado) - Pontifícia Universidade Católica de Campinas.
SAATY, T.L. The analytic hierarchy process. New York: McGraw-Hil, 287 p., 1980.

SAATY, T. Método de análise hierárquica. São Paulo: McGraw-Hill. 1991.

SAATY, T. Fundamentals of the Analytic Hierarchy Process RWS. Pittsburg. 2000.

SCHEMBRI, G.P.R. Análise do potencial de risco e classificação das barragens de rejeito da mineração no estado de Minas Gerais. Revista Científica Semana Acadêmica. Fortaleza, ano MMXVI, Nº. 000085, 2016.
Submetido em 7 de dezembro de 2018 Aceito em 30 de julho de 2019 